\title{
UPANISAD PERSPEKTIF PENDIDIKAN MODERN
}

\author{
Oleh : \\ Ida Bagus Putu Eka Suadnyana \\ (E-mail : Idabaguseka09@ gmail.com ) \\ Krisna Sukma Yogiswari \\ (E-mail : yogiswarikrisna@gmail.com) \\ Sekolah Tinggi Agama Hindu Negeri Mpu Kuturan Singaraja
}

\begin{abstract}
Book of the Upanishads is a book that can guide students to improve Sradha and Bhakti presented to Ida Sang Hyang Wasa Widhi. Upanishad is taken from the word "Upa" (near), "Ni" (Under), "Sad" (sit), so Upanishads means sitting under nearby. A group of students sitting near the teacher to learn the teachings of the Upanishads, reviewing the most essential issues and convey to students near them. This Upanishad it is a philosophical review of the Vedas, because every part of the review by the Upanishads Vedas, Upanishads thus derived contents and refer to the Vedas. education antiquity held in pesraman-pesraman or solitary place away from the crowds unlike now where the different methods and systems already using the system class. Along with the development of science and technology education pattern began to develop it, but it would be nice if such technological progress offset by an increase in human resources to the development of technology is not abused and still refers to the teachings of the religion, so it is important for the teacher to inculcate patterns of previous education contained in the Upanishads directed to students so that lessons and more easily understood by students. It is also important for a teacher to instill confidence in the Lord to the students, because the trust and of understanding the existence of Ida Sang Hyang Widi Wasa will give rise to positive thinking finally able to be applied by the students into a concrete action in accordance with the rules of religion.
\end{abstract}

Keywords: Upanisad, Perspective, Modern Education

\section{PENDAHULUAN}

Veda diyakini dan dipedomani oleh umat Hindu sebagai satu-satunya sumber bimbingan dan informasi yang diperlukan dalam kehidupan sehari-hari ataupun untuk waktu tertentu. Diyakini sebagai kitab suci karena sifat isinya dan yang menurunkan (mewahyukan) adalah Tuhan yang Maha Esa disebut Apauruseya. Apapun yang diturunkan sebagai ajarannya kepada umat manusia adalah ajaran suci terlebih lagi bahwa isinya itu memberikan petunjuk-petunjuk atau ajaran untuk hidup suci.

Dalam Veda ada kitab yang salah satunya kitab Upanisad. Kitab Upanisad jumlahnya ada sekitar 108 buah. Kitab Upanisad adalah kitab-kitab yang merupakan penjelasan terhadap kitab Aranyaka. Menurut Made Titib (1996) kitab-kitab Aranyaka 
membayangi (diambil alih) oleh kitab-kitab Upanisad, sama halnya dengan kitabkitab Brahmana membayangi (diambil alih) oleh kitab-kitab Aranyaka. Para Brahmacari mempelajari kitab-kitab Samhita, para grahasta mempelajari kitab-kitab Brahmana yang menjelaskan tentang tugas dan kewajiban atau upacara sehari-hari sedangkan para Wanaprasta mempelajari kitab-kitab Aranyaka, demikian pula para samyasin khusus mempelajari kitab-kitab Upanisad yang mengandung ajaran filsafat. Model pembelajaran dalam Upanisad secara umum dirujuk pada pengertian secara etimologi dari kata Upanisad itu sendiri yang mengandung arti "duduk di bawah dan didekatnya".

Sekelompok murid duduk dekat sang guru untuk mempelajari ajaran Upanisad, mengkaji masalah yang paling hakiki dan menyampaikan kepada siswa di dekat mereka. Orang-orang suci atau guru ini mengambil sikap tidak banyak bicara dalam menyampaikan kebenaran. Mereka menuntun siswa untuk tetap berpikiran rohani sehingga apa yang diajarkan tidak semata-mata pemahaman kognitif tetapi tercermin juga aspek psikomotorik dan afektifnya. Para guru agung dimasa yang silam tidaklah mengklaim dirinya sebagai orang yang berjasa, melainkan hanyalah memelihara dan melanjutkan ajaran kebijaksanaan kuno (Suamba, 2003:16)

Berbeda dengan kehidupan masa kini perkembangan teknologi dan informasi yang merambah hampir ke semua aspek kehidupan, secara signifikan mempengaruhi pola kehidupan manusia. Kemajuan iptek tersebut di satu sisi membawa hal-hal yang konstruktif bagi kehidupan manusia dan disisi lain iptek memberi sumbangan yang signifikan (nyata) ke arah destruktif bagi kehidupan manusia (Gorda, 2005 : 1). Untuk meminimalkan dampak negatif atau pemanfaatan iptek ke arah kesengsaraan hidup manusia adalah penting bila pembentukan kecerdasan intelektual manusia dijiwai oleh nilai-nilai spiritual yang bersumber pada ajaran Veda. Dalam hal ini sangat relevan bila kita menghayati dan merenungkan pernyataan dari Albert Einstein, yakni "Science without religion is lame, religion without science is blind" (ilmu tanpa agama akan lumpuh, sedangkan agama tanpa ilmu akan buta).

Kehidupan sekarang telah menampilkan begitu banyak perubahan yang sangat pesat, seperti kemajuan iptek, dan pesatnya perkembangan informasi yang berpengaruh pada pola pikir manusia, namun pada kehidupan moral justru mengalami degradasi moral, seakan-akan moral itu tidak memiliki kegunaan yang berarti, 
batasan-batasan moral sengaja dilanggar. Dampak negatif ini sangat nyata ada pada generasi muda, terutama ketika mereka ada di lingkungan sekolah. Tingkah laku, etika, dan kesopanan anak muda sekarang sangat memprihatinkan dan cenderung menyebabkan terjadinya konflik, baik antar sesama pelajar, remaja maupun orang dewasa (Antara, 2013).

Hal ini merupakan cerminan rendahnya kualitas output pendidikan agama Hindu di lembaga pendidikan formal. Study empiris yang dilakukan oleh Blazley menunjukkan bahwa pembelajaran selama ini cenderung bersifat teoritik dan tidak terkait dengan lingkungan peserta didik dan hal ini menyebabkan pembelajaran tidak menarik (Tanu, 2011). Kekhawatiran orang tua, guru, dan masyarakat yang berkaitan dengan moral, etika, dan sopan santun anak-anak belakangan ini harus segera dicermati dan dikaji bersama. Dalam konteks ini semua pihak harus segera ambil bagian saling membantu menanggulangi agar anak kembali santun di hadapan orang tua, hormat di hadapan guru, dan berbudi pekerti luhur di tengah masyarakat. Mengupayakan hal itu, Mahatma Gandhi (1988:176) menyatakan penting sekali diskontruksi suatu model pendidikan sempurna, dengan membangkitkan sifat-sifat terbaik yang melekat pada setiap orang, guna menumbuhkembangkan jiwa-jiwa kedewataan manusia melalui pendidikan bathin. Suatu pendidikan yang dapat menampilkan sifat-sifat terbaik secara menyeluruh yang ada dalam kepribadian (personal) seorang anak atau manusia, caranya dengan memadukan fungsi tubuh, kekuatan akal dan kesadaran jiwa secara sinergis dan harmonis dalam format pendidikan moralitas guna membangkitkan sifat-sifat dan atau karakter terbaik bagi setiap orang. Kalau pada jaman dulu ada hutan dan ada tempat sunyi untuk para murid duduk di dekat kaki guru, apakah itu masih dimungkinkan untuk jaman modern yang sudah tidak mendukung untuk melakukan hal itu? Bukankah sulit untuk duduk di dekat guru seperti jaman dulu, padahal sekarang sistem belajarnya menggunakan kelas-kelas dan para siswanya duduk di bangku? Apakah masih dimungkinkan sistem Upanisad itu diterapkan? 


\section{HASIL PENELITIAN DAN PEMBAHASAN}

1. Upanisad sebagai Landasan Pendidikan Agama Hindu

Kata Upanisad didapat dari akar kata "Sad" dengan prefik "Ni" yang artinya duduk. yang dimaksud dengan duduk ini adalah aktifitas duduk di bawah dekat dengan guru spiritual dan bersikap yang baik mendengarkan ajarannya. Yang dimaksud dengan Upanisad adalah suatu teks kuno yang isinya merupakan bagian akhir dalam ajaran Hindu. Kata Upanisad sendiri dari bahasa sansekerta yang mengandung arti dan makna duduk di hadapan kaki guru agar bisa menerima pendidikan dan pengajaran, karena itu sebagian besar dari kitab tersebut berupa dialog yang terjadi antara Maharsi dengan Tuhan. Isi pendidikan dan pengajaran dalam dialog ini sangat kompleks, namun intinya berupa semangat dalam berfikir secara bebas dalam ajaran agama.

Pada umumnya orang yang baru pertama kali mempelajari kitab ini sering merasa kebingungan, apalagi jika dilakukan secara tergesa-gesa, namun setelah dipelajari secara teratur dan disiplin, maka bisa lebih memahami dan menghayatinya. Semua ajaran yang tertulis dalam kitab Upanisad ini merupakan sebuah kebenaran yang tidak saja harus diketahui tapi juga dipahami sekaligus dipraktekkan dalam kehidupan sehari-hari, jadi tidak hanya diucapkan atau diingat dalam pikiran saja, sebab dengan mempraktekkan ajaran ini maka proses kesempurnaan bisa terus berjalan.

Upanisad dijadikan sebagai landasan dalam pendidikan agama Hindu karena isi dari Upanisad adalah merupakan ulasan filosofis dari Veda dimana Veda merupakan sumber dari ajaran agama Hindu, setiap kegiatan umat hindu tentunya berpedoman pada ajaran Veda. Dilihat dari kronologisnya Upanisad adalah ajaran yang mengikuti Vedanta yang lebih sering disingkat sebagai kitab Veda. Jendra (2006:10) menegaskan bahwa Upanisad merupakan pengetahuan yang dapat melenyapkan kebodohan manusia sejak lahir, atau yang mengajarkan tentang sikap dan perilaku untuk mencapai Brahman, terkait dengan pernyataan di atas maka sangatlah cocok jika Upanisad dijadikan landasan dalam pendidikan agama Hindu pada era modern.

Upanisad menekankan bahwa belajar merupakan esensi hidup manusia. Sejak lahir sebagai bayi, dia belajar menyusui dan mengenal orang tua. Dia kemudian 
belajar merangkak, berdiri, mengenal bahasa, menjadi dewasa, dan menjadi orang tua. Upanisad menjelaskan masih ada yang mesti dipelajari. Belajar melewati jalan kematian (durga). Mempelajari jalan mencapai moksa (ganesha) sebagai tujuan pelaksanaan hukum suci ketuhanan (dharma).

Secara tradisi ada dua cara belajar dalam ajaran Upanisad. Belajar secara interaktif dengan guru (gurukula) dan belajar tanpa bimbingan guru (swadhyaya). Terkait dengan hal ini, sumber-sumber yang digunakan untuk mendukung proses belajar terdiri dari sumber yang berasal dari guru (gurutah) dan sastra (sastratah) yang dapat dilihat dalam bentuk pustaka maupun referensi lainnya. Yang dimaksudkan dengan guru adalah orang tua sendiri (guru reka), guru profesional (guru waktra) dan pemerintah (guru wisesa). Bahkan pada tahap tertentu sebagai sumber belajar adalah Brahman (Tuhan sebagai Guru Swadhyaya) dalam saktinya sebagai sumber dari segala sumber pencerahan (Brahma) dan ilmu pengetahuan (Saraswati).

Tradisi Hindu menggambarkan bahwa setelah masa pengawasan total orang tua, ada masa menempuh pendidikan formal dibawah bimbingan guru profesional. Masa ini diawali dengan proses inisiasi dalam mengukuhkan kesiapan calon siswa untuk belajar. Inisiasi dilakukan melalui persembahan api suci sebagai simbol api semangat belajar kepada guru. Mulailah kegiatan gurukula dilaksanakan. Inisiasi yang mengawali proses belajar ini tidak diadopsi begitu saja dalam pendidikan Hindu di Indonesia. Proses inisiasi tetap dilaksanakan melalui pawintenan. Kesiapan dikembangkan melalui Saraswati Puja yang dipimpin manggala yadnya

\section{Pembelajaran Dalam Ajaran Upanisad}

Belajar menurut Upanisad merupakan usaha pendewasaan diri melalui berbagai perubahan berdasarkan pengkondisian lingkungan secara eksternal (hal ini sesuai dengan teori behavioris) dan kesadaran mandiri menyusun bahannya secara internal (hal ini sesuai dengan teori contructivis). Usaha membentuk manusia dewasa berkepribadian mantap, kreatif serta berkepercayaan diri dalam mengembangkan dan menyelesaikan segala problema secara mandiri. Secara normal proses ini melibatkan antaraksi antara siswa (sisya) dengan guru dalam proses belajar (adhyaya) dan 
mengajar (adhyaapayitum) yang sekarang dikenal sebagai pembelajaran (svadhyaya adhyaapayitum atau svadhyaya pravacane).

Kata kunci pembelajaran dalam Upanisad adalah siap. Kesiapan dari kedua belah pihak, murid maupun guru. Itulah yang menjadi alasan mengapa saat Sukesa, Satyakama, Gargya, Kausalya, Bhargawa, dan Kabandhi datang untuk mempelajari pengetahuan suci ketuhanan, Rsi Pippalada berkata, "diamlah bersamaku setahun dengan mengembangkan keingintahuan (tapasa), pemusatan perhatian (brahmacaryena) dan kepercayaan (shraddaya)" (Prsna Upanisad 1 dan 2). Makna kesiapan sangat penting. Kalau tidak siap maka pembelajaran percuma diselenggarakan. Itulah yang menyebabkan sutra-sutra Hindu secara umum dimulai dengan kata 'atha', saat ini, saat siap secara menyeluruh menginternalisasi pengetahuan.

Upanisad menekankan pembelajaran dengan pendekatan partisipatif. Siswa aktif menyusun pengetahuan sendiri dengan berbagai macam cara atau metode pembelajaran seperti mengembangkan kemampuan bertanya, berdiskusi, meneliti perilaku alam dan lain-lain. Sebagai contoh adalah Satyakama yang dianjurkan Rsi Gautama menyusun pengetahuan secara mandiri dengan meneliti perilaku dan tandatanda semesta sebelum mengkaji landasan tattwa secara mendalam (Chandogya Upanisad).

Upanisad menjamin siswa mengembangkan kreatifitas berinovasi melewati garis-garis kebiasaan dalam pembelajaran. Walaupun kreativitas pembelajaran semacam itu muncul dari hal yang sangat tidak mungkin dilakukan sekalipun. Naciketa yang tidak puas dengan pencapaian orang tua dan masyarakat yang terikat pada kebiasaan pembelajaran yang sudah mentradisi, melakukan eksperimen dalam jalan kematian (Katha Upanisad). Keberanian berkreasi dalam inovasi ini membawa Naciketa pada pencapaian perilaku hidup yang luar biasa. Perilaku yang dapat digunakan untuk memperbaiki lubang-lubang kelemahan batasan kebiasaan pada pembelajaran secara umum.

Aktivitas pembelajaran yang umum dilakukan pada tradisi pembelajaran Upanisad adalah melalui pembelajaran langsung dengan pendekatan individual maupun klasikal, pembelajaran melalui kerja kelompok, dan pembelajaran berbasiskan masalah yang ditemui secara faktual maupun abstrak. Polanya tentu 
berbeda sesuai dengan subjeknya, anak-anak yang belum dewasa atau orang dewasa. Aktivitas tersebut pada jaman Mahabarata digambarkan dengan pembelajaran formal yang dilalui putra-putra Pandu dan Drestarata dibawah bimbingan Guru Drona (Dronacharya) pada saat mereka masih belum dewasa. Pola yang berbeda mereka peroleh ketika melakukan pembelajaran dibawah bimbingan Krishna. Aktivitas pembelajaran sedemikian rupa juga banyak ditemui dalam berbagai Upanisad sampai ke kitab panca tantra yang penuh dengan cerita-cerita simbolis kehidupan. Aktivitas pembelajaran tersebut masih tercermin sampai sekarang pada kegiatan pasraman sampai kegiatan universitas-universitas berbasiskan Veda.

Pembelajaran menurut tradisi Upanisad diorientasikan untuk memudahkan dalam menjalani kehidupan. Kenyataan hidup digali secara mendalam dengan berbagai pendekatan observatif, praktis, teoretis, dan visualisasi sehingga dapat difahami secara holistik, tidak sepenggal-sepenggal apalagi tidak saling mengait. Dengan demikian, pembelajaranpun mesti difahami secara holistik. Hal-hal sedemikian rupa yang menjadi penyebab PBI (problems base instruction) dan RBI (researches base instruction) dengan basis pramana sastra, anumana, dan prtyaksa yang didukung oleh likita, bukti dan saksi banyak muncul dalam pembelajaran sesuai Veda. Sehingga CTL (contextual teaching and learning) dan lain-lain bukan pendekatan baru dalam pembelajaran menurut Veda yang menekankan pada "belajar sepanjang masa dan belajar secara smart".

RBI menyebabkan pembelajaran mempunyai basis yang kuat dari segi materi dan prosesnya. PBI menyebabkan pembelajaran menjadi selalu kini dan tidak ketinggalan jaman. Jangkauan riset yang tidak sekedar berorientasikan pada hasil penelitian tetapi prediksi terhadap pembelajaran lanjut (advant and future studies) sedemikian rupa menyebabkan pembelajaran yang tertuang dalam ajaran Upanisad mempunyai jangkauan kedepan dan tetap relevan sepanjang jaman, yang dapat diterapkan pada pendidikan anak (pedagogi) maupun pendidikan orang dewasa (andragogi). Adapun Beberapa model pembelajaran yang dapat digunakan oleh guruguru di Pasraman antara lain dengan menggunakan metode pembinaan agama Hindu yang dikenal dengan sad dharma, yaitu : 
- Dharma Tula, yaitu Tula artinya timbang, Dharmatula adalah pertimbangan pikiran, berdiskusi, atau turun rembug tentang ajaran Dharma untuk pencerahan serta pendalaman agama (Sura, 1999:12). Dharmatula adalah salah satu pola pendidikan hindu dalam Upanisad yang dilakukan melalui diskusi agama untuk mendapatkan kesamaan persepsi dalam meningkatkan penghayatan pada nilainilai agama yang dianut (Wiana, 2009:74). Tujuan metode dharma tula adalah sebagai salah satu metode yang dapat dipakai sarana untuk melaksanakan proses pembelajaran agar siswa lebih aktif, dengan harapan para siswa nantinya mampu dan memiliki keberanian untuk mengemukakan pendapat serta dalam rangka melatih siswa untuk berargumentasi dan berbicara tentang keberadaan Hindu. Adapun 3 pedoman dalam berdharmatula yaitu sebagai berikut (Wiana, 2009:75)

\section{Sastra Wada}

Sastra adalah hukum-hukum atau ajaran-ajaran agama yang bersumber dari kitab suci yang telah tertulis, Wada artinya berbicara, Sastra Wada artinya berbicara dalam Dharmatula hendaknya berpegang teguh pada kitab-kitab suci yang tertulis seperti Catur Veda, Dharmasastra, Bhagawad Gita, Sarasamuscaya, Upanisad, dan lain sebagainya.

\section{Budhi Wada}

Yang dimaksud dengan Budhi Wada adalah peserta Dharmatula yang berbicara harus berdasarkan kesadaran Budhi yang tinggi, tidak boleh didominasi oleh emosi atau rasio saja atau dengan kata lain pembicara harus didorong oleh nalar yang tinggi.

\section{Prema Wada}

Prema Wada artinya setiap peserta yang ikut dalam Dharmatula tidak ada yang saling membenci karena Dharmatula harus diselenggarakan berdasarkan rasa kasih sayang (prema), Dharmatula dapat dilakukan melalui pembahasan umum dari ajaran agama Hindu yang ingin didalami. Kasih yang dimaksud disini adalah kasih yang murni seperti kasih sayang orang tua kepada anaknya. Kalau kasih dapat kita semayamkan dalam Dharmatula maka karunia tuhan 
akan lebih dapat diwujudkan selain itu pemahaman-pemahaman dharmapun akan lebih mudah dicapai. Suatu Dharmatula akan mencapai sukses apabila kasih itulah yang pertama-tama diwujudkan.

- Dharma Wacana, artinya berbicara mengenai ajaran agama atau Dharma, yang dimaksud dengan pola pendidikan dharmawacana adalah ceramahceramah agama yang bertujuan untuk memperluas wawasan dan memperdalam penghayatan nilai spiritual agama Hindu itu sendiri (Wiana, 2000:73).

- Dharma Gita, adalah salah satu cara untuk membangkitkan kekuatan suci yang ada dalam diri kita. Kekuatan suci itu terdiri dari atman yang diselubungi oleh Panca Maya Kosa. Panca Maya Kosa itu adalah (1) Anna Maya Kosa t lapisan yang terbuat dari sari makanan, (2) Prana Maya Kosa yaitu lapisan yang terbuat dari Prana atau kekuatan vital yang disebut juga dengan energi, (3) Mano Maya Kosa yaitu lapisan yang terbuat dari manah atau pikiran, (4) Vijnana Maya Kosa yaitu lapisan yang terbuat dari Ilmu pengetahuan, (5) Ananda Maya Kosa yaitu lapisan tubuh yang terbentuk dari kebahagiaan. Jika kelima selubung atman ini lebih kuat maka kekuatan suci atman tidak dapat terpancar seperti matahari yang diselubungi mendung gelap (Wiana, 2000:75).

- Dharma Yatra, yaitu usaha meningkatkan pemahaman dan pengalaman pembelajaran agama Hindu melalui persembahyangan langsung ke tempattempat suci.

- Dharma Sadhana, adalah realisasi ajaran dharma yang harus ditanamkan kepada siswa dalam rangka meningkatkan kualitas diri untuk selalu taat dan mantap dalam menjalankan ajaran agama Hindu.

- Dharma Santi, yaitu kebiasaan saling memaafkan diantara sesama umat, bahkan diantara umat beragama.

Sedangkan siswanya atau sisyanya duduk di bawah sambil mendengarkan gurunya (acarya) melakukan pencerahan jiwa bagi dirinya maupun orang lain. Ini merupakan ciri khas dari kitab-kitab Upanisad yaitu bentuk penyajian ajaran yang disampaikannya, yaitu selalu berbentuk dialog antara murid (sisya) yang bertanya kepada seorang guru (acarya) dalam pendidikan pasraman (ashram). Rupanya bentuk tanya jawab semacam ini sangat disenangi dan efektif terbukti dari buku-buku yang 
tersusun pada masa kemudiannya sebagian besar memakai bentuk tanya jawab. Bentuk tanya jawab ini antara guru dengan sisya/siswa terdapat dalam kitab-kitab Tattwa seperti wrhaspatitattwa, Ganapatitattwa, Agastayaparwa dan lain-lain.

\section{Implikasi Pola Pendidikan Upanisad Dalam Pendidikan Modern}

Siswa (sisya) merupakan individu yang unik, artinya tidak ada dua orang siswa yang sama persis, setiap siswa memiliki perbedaan satu sama lainnya. perbedaan itu terdapat pada karakteristik psikis, kepribadian, dan sifat-sifatnya. Perbedaan individu ini akan berpengaruh pada cara dan hasil belajar siswa, oleh sebab itu perbedaan individu perlu diperhatikan oleh guru dalam proses pembelajaran di kelas sehingga strategi dan model pembelajaran yang digunakan dapat berhasil optimal.

Siswa dituntut untuk memberikan perhatian terhadap semua rangsangan yang mengarah ke arah pencapaian tujuan belajar. Adanya tuntutan untuk selalu memberikan perhatian ini menyebabkan siswa harus membangkitkan perhatiannya kepada segala pesan yang disampaikan guru, apalagi siswa diberikan untuk mencari pemahaman dan menemukan sendiri tentang materi yang diberikan oleh guru dalam proses pembelajaran. Pola pendidikan merupakan bagian yang penting dalam suatu proses pembelajaran oleh karena itu diperlukan suatu pola atau model pembelajaran yang benar-benar mampu meningkatkan pemahaman siswa akan suatu materi pembelajaran khususnya dalam mata pelajaran agama Hindu. Peningkatan atau pengembangan pola pendidikan akan berdampak pada siswa itu sendiri dimana siswa akan termotivasi untuk lebih belajar dan lebih meningkatkan prestasi belajarnya (Jaya, 2010:102).

Implikasi dari pola pendidikan Upanisad terhadap siswa (sisya) akan mampu memotivasi siswa dalam meningkatkan daya kreatifitas berfikirnya. Siswa akan menyadari bahwa motivasi belajar yang ada pada dirinya harus dibangkitkan dan mengembangkan bakat sendiri secara terus menerus. sebagai pelaku utama dalam proses pembelajaran maupun belajar, siswa akan selalu aktif memproses dan mengolah secara perlahan dalam belajarnya, untuk itu siswa akan selalu aktif secara fisik, intelektual, dan emosionalnya (Riyanto, 2010:76). 
Implikasi lain dari Pola pendidikan dalam Upanisad dikaitkan dengan pendidikan modern terhadap siswa adalah tercermin pada terlihatnya perubahan pada tingkah laku dan kepribadian siswa serta motivasi siswa akan belajar semakin meningkat. Perubahan tersebut antara lain : 1) Meningkatnya daya kreatifitas, 2) Meningkatnya daya inovasi siswa dalam belajar. 3) Tumbuhnya sikap kompetitif dalam belajar. 4) Meningkatnya sikap kemandirian siswa. Sedangkan di dalam kelas siswa akan tampak lebih desiplin, serius dalam belajar serta kompetitif dalam prestasi baik prestasi akademik maupun non akademik ( Jaya, 2010: 103).

Dalam kaitannya dengan pernyataan di atas, Riyanto, (2010 : 76) menegaskan bahwa dalam pembelajaran guru harus mampu menggunakan strategi agar proses pembelajaran terlaksana dengan optimal. Apabila pola pembelajaran terdahulu diterapkan dalam pendidikan modern akan berakibat pada siswa yaitu, siswa akan lebih aktif dalam mewujudkan perilaku belajarnya dan siswa akan lebih mudah memahami materi yang diajarkan oleh guru yang menyebabkan terjadinya perubahan tingkah laku dalam belajarnya serta secara tidak langsung Sradha dan Bhakti kehadapan Tuhanpun akan lebih ditingkatkan lagi.

Davies (dalam Riyanto, 2010 : 76) mengatakan hal apa pun yang dipelajari siswa, maka ia akan mempelajari sendiri apa yang diberikan oleh guru. Tidak ada seorangpun dapat melakukan kegiatan belajar tersebut untuknya. Dimana implikasi dari penerapan model pendidikan Upanisad dalam pendidikan modern yang digunakan oleh guru akan membuat siswa semakin termotivasi untuk selalu belajar dan meningkatkan Sradha dan Bhaktinya kehadapan Tuhan. Seorang siswa belajar lebih banyak bilamana setiap langkah segera diberikan penguatan oleh guru (Davies dalam Riyanto, 2010:77).

\section{KESIMPULAN}

Sistem Upanisad yang menghasilkan ajaran yang sekarang kita sebut dengan kitab Upanisad masih tetap bisa dijalankan sampai saat jaman modern ini sekalipun. Perlu kita ingat bahwa sifat Veda adalah anadi dan ananta, yang artinya akan tetap relevan dengan perkembangan jaman sampai kapanpun. Masalahnya adalah kita kesulitan untuk mencari guru kerohanian yang benar-benar mampu mengajarkan filsafat Upanisad seperti jaman dulu. Selain itu juga semakin sedikit manusia modern yang tertarik untuk belajar agama sungguh-sungguh, karena mereka lebih tertarik 
untuk memuaskan nafsu dan kepuasan indrianya. Jadi masalahnya bukan ajaran Vedanya yang tidak sesuai jaman, tapi manusianya yang memang tidak mau lagi bersusah-susah menjalankan ajaran-ajaran Veda.

\section{DAFTAR PUSTAKA}

Antara, I Made Oka.2013. "Nilai-Nilai Pendidikan Agama Hindu Dalam Bhisma Parwa". Skripsi. Tidak Diterbitkan. Fakultas Pendidikan Agama Dan Seni. Universitas Hindu Indonesia Denpasar.

Gorda, I Gusti Ngurah. 1996. Etika Hindu dan Prilaku Organisasi. Singaraja : STIE Satya Dharma.

Jaya, I Kadek Arta. 2010. Strategi Guru Pendidikan Agama Hindu dalam Mengimplementasikan Kurikulum Tingkat Satuan Pendidikan di SMP Negeri 2 Selat. Skripsi. Tidak diterbitkan. Program Pendidikan Agama Hindu. Fakultas Pendidikan Agama Dan Seni. Universitas Hindu Indonesia. Denpasar.

Jendra,Wayan.2006. "Intisari Upanisad”. PT Empat Warna Komunikasi.Denpasar.

Gandhi, M. K., 1988, Semua Manusia Bersaudara, Kehidupan dan Gagasan Mahatma Gandhi Sebagai Diceritakannya Sendiri, diterjemahkan oleh Kustiniyati Mochtar , Judul asli: All Men My Brothers: Life and Tought of Mahatma Gandhi as Told in Him own Word, Yayasan Obor Indonesia, Jakarta.

Radhakrishnan, 1953. "Upanisad-Upanisad Utama “, Jakarta : Yayasan Dharma Sarathi.

Riyanto, Yatim.2010. Paradigma Baru Pembelajaran sebagai Referensi Bagi Pendidik dalam Implementasi Pembelajaran yang Efektif dan Berkualitas.Jakarta: Kencana Prenada Media Group

Suamba, I.B Putu. 2003. Dasar-Dasar Filsafat India. Denpasar : Widya Dharma.

Sura, I Gede. 2001. Ajaran Ketuhanan dalam Agama hindu Di Bali. Makalah Disajikan Dalam Seminar Dengan Topik : "Ajaran Ketuhanan". Diselenggaran Universitas Hindu Indonesia di Denpasar.

Tanu, Ketut. 2011. "Bunga Rampai Pembelajaran Agama Hindu di Sekolah.Denpasar : Sari Kahyangan Indonesia.

Titib, I Made. 1994. “Untaian Ratna Sari Upanisad”. Denpasar : Yayasan Dharma Narada.

Wiana, I Ketut, 2000. Makna Agama DalamKehidupan.Denpasar :Pustaka Bali Post. 